\title{
Expression of Heat Shock Protein 27 in Oral Potentially Malignant Disorders and Oral Squamous Cell Carcinoma: An Immunohistochemical Study
}

\author{
${ }^{1}$ Annavajjula Saileela, ${ }^{2}$ Spoorthi B Ravi
}

\section{ABSTRACT}

Aim: The present study aims to estimate as well as compare the amount of immunohistochemical expression of heat shock protein 27 (HSP27) in oral potentially malignant disorders (OPMDs) and oral squamous cell carcinoma (OSCC).

Materials and methods: The study group comprised 24 cases of OPMDs, 12 OSCC cases, and 9 normal (controls) oral mucosa specimens. All sections were stained immunohistochemically with HSP27 antibody kit followed by analysis.

Results: Increased intensity of staining with statistically significant difference $(p=0.001)$ was observed in OSCC cases when compared with normal oral mucosa sections. Statistically insignificant results were obtained between OPMDs and normal tissues.

Conclusion: Due to significant increase in the staining intensity of OSCC cases when compared with normal sections, HSP27 can be possibly used as a prognostic marker in OSCC cases.

Clinical significance: Early diagnosis of malignant transformation through diagnostic markers will markedly improve the overall quality of life. Therefore, early monitoring of the expression of HSP27 in OPMDs will give an insight into their malignant transformation.

Keywords: Heat shock protein 27, Leukoplakia, Oral lichen planus, Oral potentially malignant disorders, Oral squamous cell carcinoma, Oral submucous fibrosis.

How to cite this article: Saileela A, Ravi SB. Expression of Heat Shock Protein 27 in Oral Potentially Malignant Disorders and Oral Squamous Cell Carcinoma: An Immunohistochemical Study. World J Dent 2018;9(2):101-105.

Source of support: Nil

Conflict of interest: None

\section{INTRODUCTION}

Heat shock proteins are pervasive proteins present in all the living organisms. ${ }^{1}$ They are derived from specific gene families that play a protective role during stress, thereby

${ }^{1}$ Private Practitioner, Department of Oral Pathology, Secunderabad Telangana, India

${ }^{2}$ Oral Diagnostic and Surgical Sciences Division, International Medical University, Bukit Jalil, Kuala Lumpur, Malaysia

Corresponding Author: Annavajjula Saileela, Private Practitioner, Department of Oral Pathology, Secunderabad Telangana, India, Phone: +918143234536, e-mail: saileela. annavajjula@gmail.com considered as a form of ancient defense system. A wide range of tumoral tissues expressed atypical levels of one or more HSPs. ${ }^{2}$ Heat shock proteins are classified into six families (HSP100, HSP90, HSP70, HSP60, HSP40, and small HSPs) based on molecular weight. ${ }^{3,4}$

These proteins, especially HSP27, have been associated with poor prognosis and treatment in several types of cancer that includes gastric, liver, and prostate carcinoma, osteosarcoma, rectal, lung, breast cancer, and oral cancer. ${ }^{5-7}$ The major function of HSP27 is to protect cells from apoptosis, followed by other cellular functions, such as signal transduction, differentiation, proliferation, and cellular movement. The pattern of HSP27 expression has also been correlated to malignant transformation according to Lo Muzio et al. ${ }^{6}$ In a few studies, HSP27 staining intensity was found to be higher in OSCC, dysplasia, oral lichen planus (OLP) when compared with normal tissues. ${ }^{4,6-9}$ Hence, the present study was carried out to estimate the amount of immunohistochemical expression of HSP27 and its probability of using it as a prognostic marker in OPMDs and OSCC.

\section{MATERIALS AND METHODS}

The study group comprised of 45 tissue samples. Histopathologically confirmed 24 cases of OPMDs [8 each of leukoplakia, OLP, and oral submucous fibrosis (OSMF)], 12 cases of OSCC, and 9 normal (controls) epithelial specimens from mucosa over the impacted third molar were retrieved from paraffin-embedded blocks. Blocks from 2008 to 2012 from the Department of Oral Pathology were included in the study.

- Immunohistochemistry: 3 to $4 \mu \mathrm{m}$ sections of each paraffin embedded specimens were procured by microtomy and mounted on poly-L-lysine-coated glass slides. Deparaffinization of slides with xylol, followed by rehydration with alcohol was performed. Endogenous peroxidase activity was inactivated by incubating for 5 minutes in $3 \% \mathrm{H}_{2} \mathrm{O}_{2}$ and then rinsed with phosphate-buffered saline (PBS). Sections were incubated for one hour with primary anti-HSP27 monoclonal antibody at a dilution of 1:40. In continuation to incubation, rinsing thrice in PBS, followed by secondary antibody application, was carried out. 


\begin{tabular}{ll}
\multicolumn{2}{c}{ Table 1: Scoring criteria for mean percentage of positive cells } \\
\hline Percentage of positive cells & Score \\
\hline $0-25$ & 1 \\
$25-50$ & 2 \\
$50-75$ & 3 \\
$75-100$ & 4 \\
\hline
\end{tabular}

Immunoreactivity was visualized with the aid of diaminobenzidine. Specimens were counterstained with hematoxylin and viewed under light microscope. Tissue sections of normal skin were considered as positive controls, whereas negative controls were the sections that were stained by omitting the primary antibody.

The entire procedure was blinded and evaluated by three observers and was reevaluated to avoid interobserver bias using criteria followed by Deyhimi and Azmoudeh $^{8}$ (Tables 1 and 2). The study was approved by M. S. Ramaiah Dental College ethical committee, Bengaluru.

\section{Statistical Analysis}

Statistical analysis was performed by applying chi-square test and the significance value was considered as $p=0.05$.

\section{RESULTS}

Cytoplasmic staining was observed in supra basal layers in normal section, whereas diffuse staining was observed in OSCC cases (Fig. 1). When comparison was drawn among all samples using the chi-square test, significant difference in percentage of positively stained cells and intensity of staining was noted between the samples ( $p=0.001,0.002)$. The OSCC cases showed high intensity followed by dysplastic lesions, OSMF, normal mucosa, and lichen planus cases (Graphs 1 and 2).

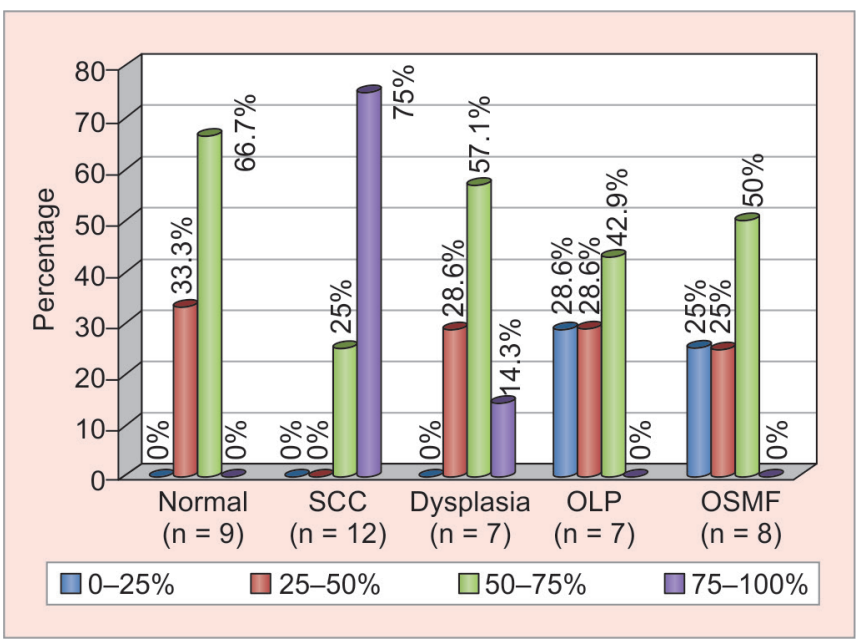

Graph 1: Percentage of positively stained cells in normal, OSCC, dysplasia, OLP, and OSMF
Table 2: Scoring criteria for staining intensity

\begin{tabular}{ll}
\hline Intensity of staining & Score \\
\hline Nondetectable & 0 \\
Very low & 1 \\
Low & 2 \\
Moderate & 3 \\
High & 4 \\
\hline
\end{tabular}
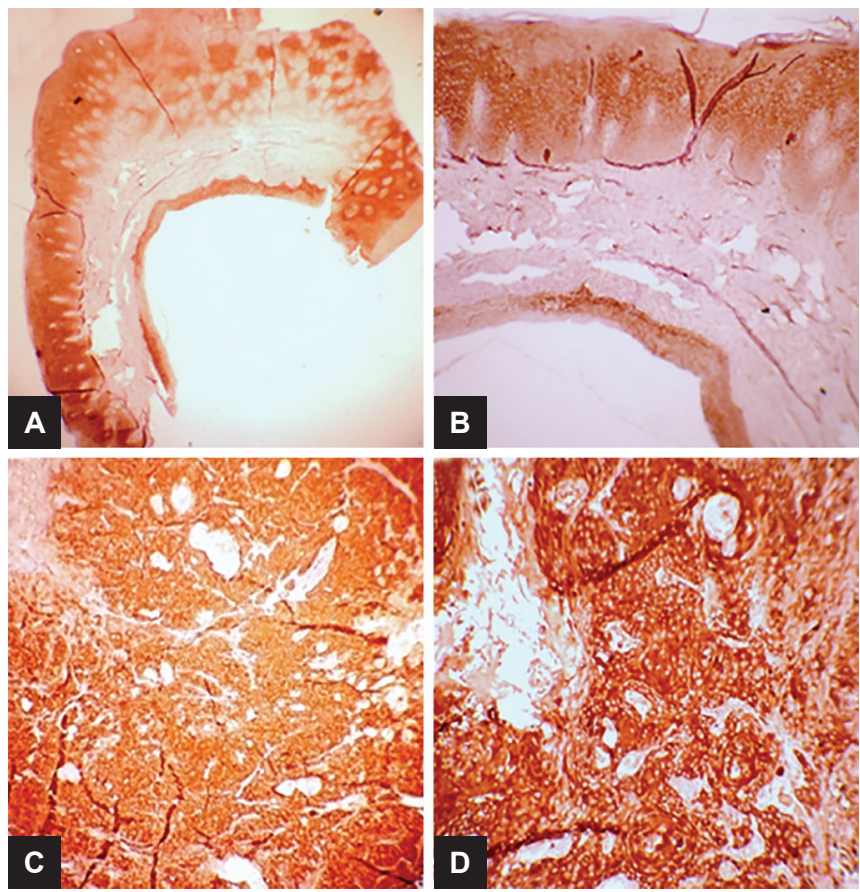

Figs 1A to D: (A, B) HSP27 staining suprabasal layers in normal tissue sections ( $4 \times$ and $10 \times)$. (C, D) Increased HSP27 staining in OSCC tissues (10x and $40 x$ )

Furthermore, comparison was carried out between OPMDs, OSCC, and normal mucosal sections. The percentage of positively stained cells and the intensity of staining were significantly higher in OSCC cases when compared with normal sections $(p=0.002,0.001)$. No

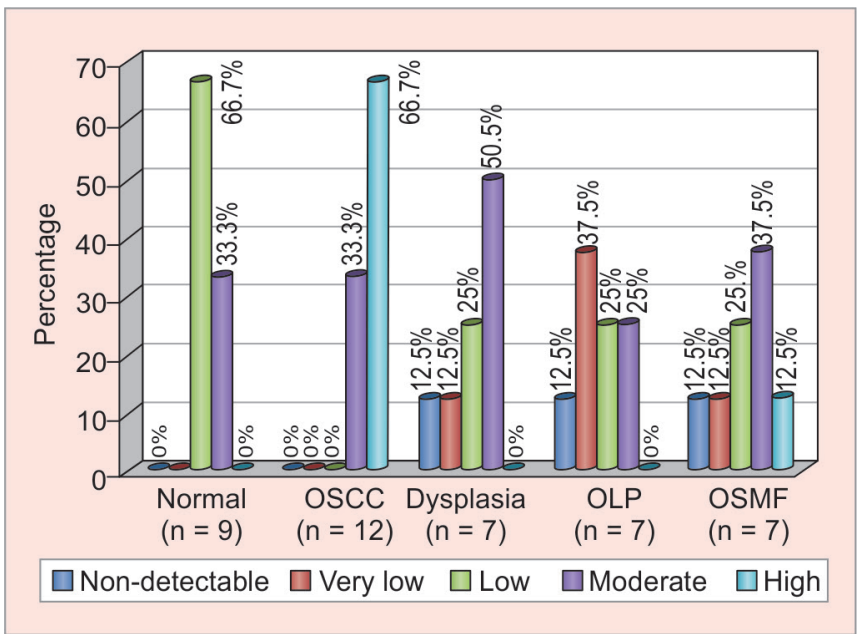

Graph 2: Intensity of staining in normal, OSCC, dysplasia, OLP, and OSMF 

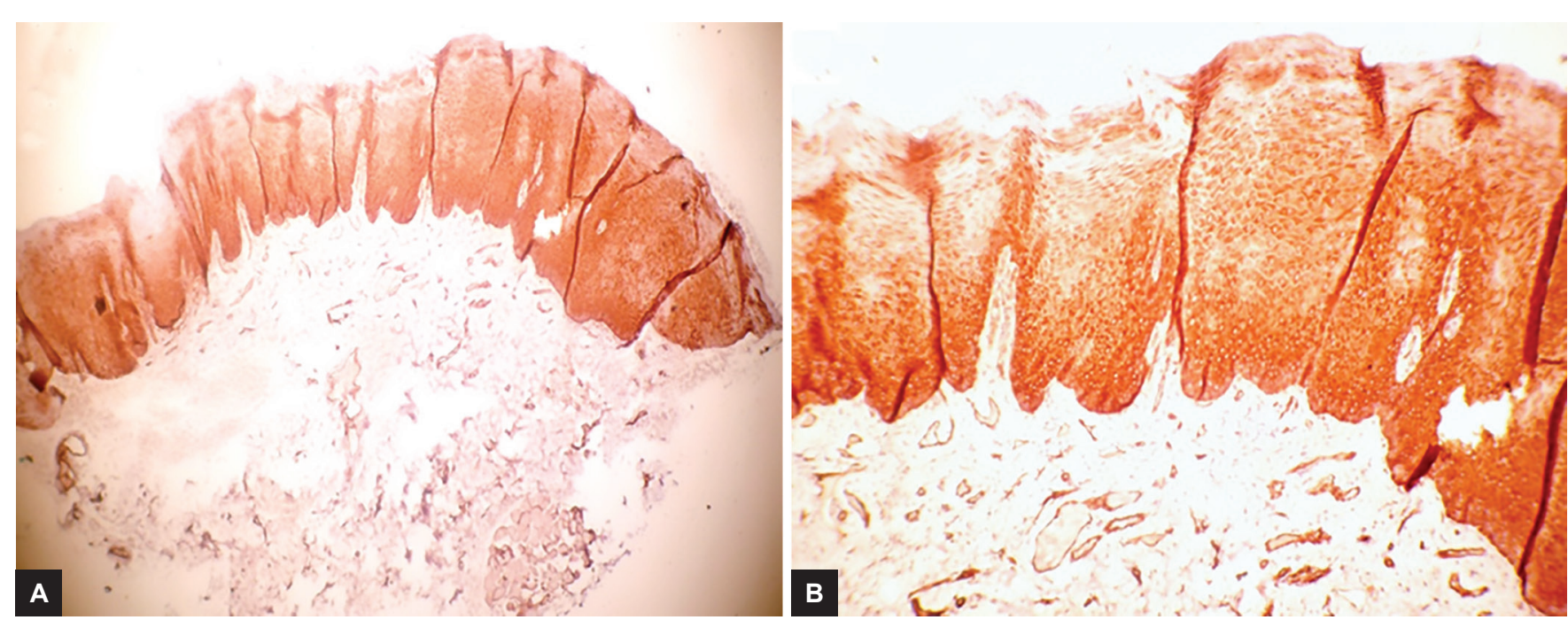

Figs 2A and B: HSP27 staining in dysplasia ( $4 \times$ and $10 \times$ )

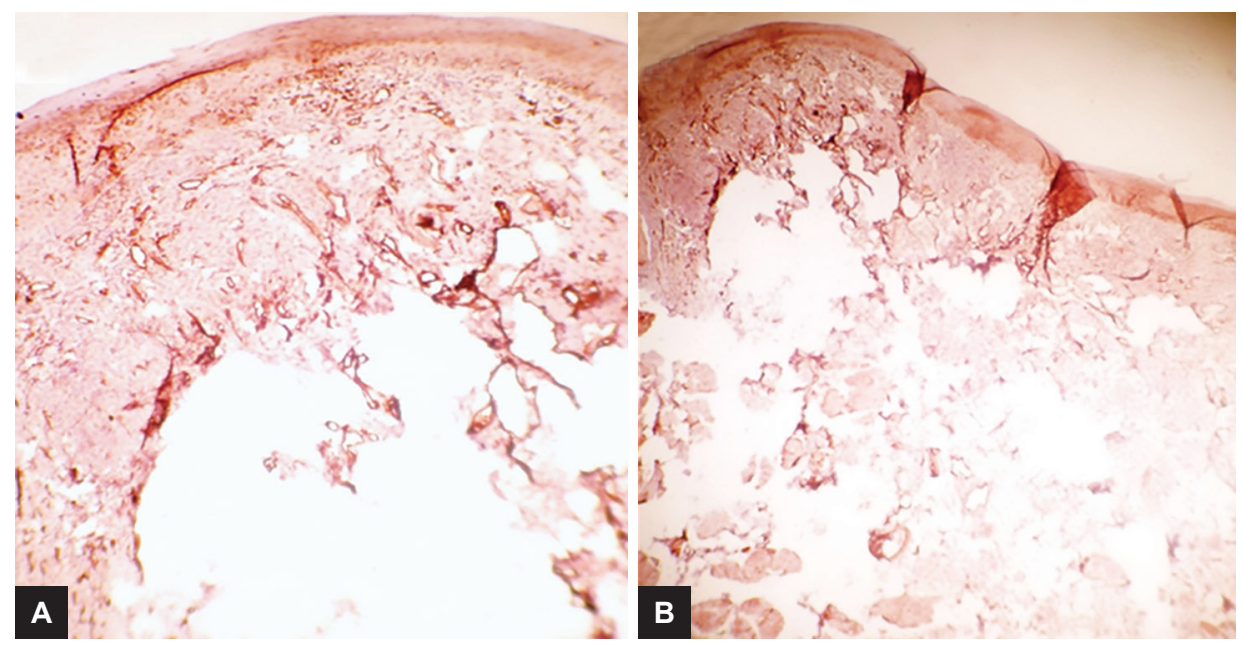

Figs $3 A$ and B: HSP27 staining in OSMF (10x)

significant difference in the percentage of positively stained cells and intensity of staining between dysplasia, OLP, and OSMF cases had been observed when compared with normal tissues $(\mathrm{p}=0.504,0.223$, and $0.279 ; \mathrm{p}=0.251$, 0.292, and 0.104) (Figs 2 to 4).

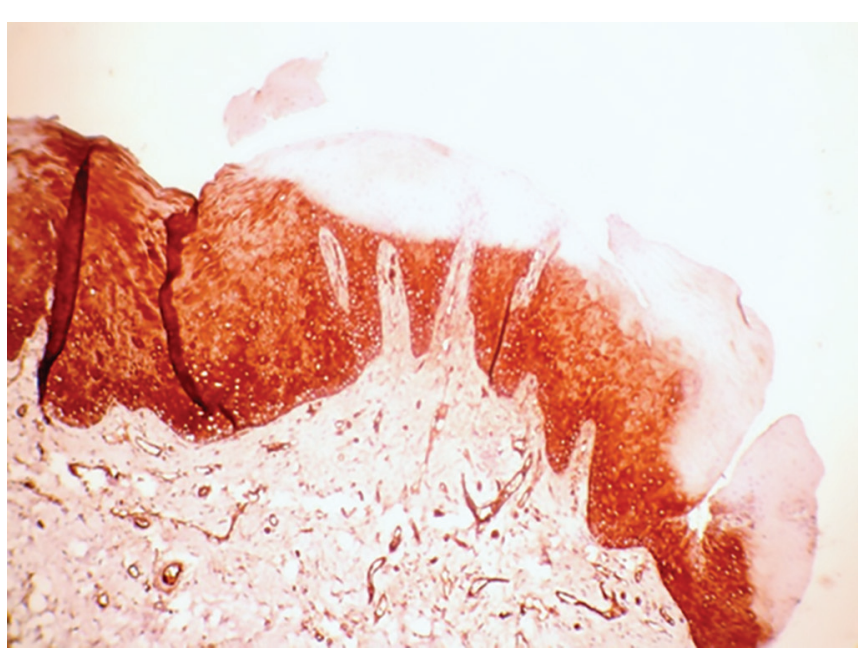

Fig. 4: HSP27 staining in lichen planus (10x)

\section{DISCUSSION}

Ritossa observed temperature-induced specific genes activation in the salivary glands of Drosophila melanogaster followed by those genes were named as "HSPs."10 However, this term is a misnomer, as they can be induced by many other stresses, such as infection, inflammation, exercise, exposure of toxins (like ethanol, arsenic, trace metals, heavy metals, solvents, effluents, pesticides, and ultraviolet light), starvation, and oxygen deprivation. ${ }^{10}$ In order to prevent damage, mutilation of cells occurs either through apoptosis or heat shock response. In other instances, cells undergo unfavorable alterations resulting in expression of group of stress genes which in turn synthesize HSPs. ${ }^{1}$ According to the previous literature, HSP27 shows a strong association with OSCC. ${ }^{6,11}$

In the present study, we evaluated the expression of HSP27 in OSCC cases and found it to be increased in expression compared to the normal mucosa expression compared with normal oral mucosa. Our results are consistent with those of Tekkesin et $\mathrm{al}_{1}{ }^{4}$ Deyihimi and 
Azmoudeh, ${ }^{8}$ Mese et al, ${ }_{1}^{12}$ and Lo et $\mathrm{al}^{13}$ studies. Increased expression could be due to:

- Inhibition of mitochondrial apoptosis through preventing cytochrome $C$ and procaspase function, thereby contributing to one of the known mechanisms of cancer development.

- Production of free radicals and also the action of increased cell resistance towards oxidative damage. Free radicals are usually released in malignancy cases.

Moreover, we derived no statistical significant difference between epithelial dysplasia cases (leukoplakia) and normal tissues. Our findings are similar to that of Leonardi et al, ${ }^{14}$ Epivatianos et al, ${ }^{15}$ and Seoane et al. ${ }^{16}$ According to Leonardi, a hypothesis was put forward for HSP27 expression in dysplasia cases. Increased expression during inflammation may protect cells, and a decrease in dysplasia cases could impair the protective mechanism by helping in the transformation into OSCCs. Tekkesin's study states that the expression of HSP27 in dysplasia is at par with OSCC cases, but is higher when compared with normal tissues.

Arecoline, a component in arecanut, is cytotoxic to oral fibroblasts by generating oxidative stress. Chang evaluated the expression of HSP27 in arecoline-induced tumors and stated that it acts as a clinical marker for tumor progression. In a study done by Lee et al, ${ }^{17} \mathrm{HSP} 27$ expression is increased in cases of areca quid chewingassociated OSCC cases. This suggests that areca quid chewing may contribute to the pathogenesis of OSCCs via HSP27 expression. However, in the present study, no correlation was derived between OSMF and HSP27 expression.

Our study shows no significant difference in the intensity of staining between OLP and normal tissues. But according to Garcia-Garcia et al, ${ }^{9} \mathrm{HSP} 27$ plays a role in OLP pathogenesis. The feature which was found to be common when compared to the above study is less HSP27 staining in superficial layers of lichen planus cases. Two reasons that were quoted by Garcia for lesser staining of superficial layers quoted in the study are:

1. The superficial layer shows loss of differentiation, making the layer more susceptible to chemical carcinogenesis.

2. It is composed of keratinized keratinocytes in which adsorption of the staining is not properly performed.

\section{CONCLUSION}

Our study demonstrated a significant increase in the staining intensity in OSCC cases compared with normal sections. No statistically significant difference was found between epithelial dysplasia, OLP, and OSMF cases in comparison with normal tissues. Hence, HSP27 can be used as a prognostic marker of OSCC. Additional studies may be required to obtain a correlation between OPMDs and normal tissues with a larger sample size.

\section{REFERENCES}

1. Whitley D, Goldberg SP, Jordan WD. Heat shock proteins: a review of the molecular chaperones. J Vasc Surg 1999 Apr;29(4):748-751.

2. Jolly C, Morimoto RI. Role of the heat shock response and molecular chaperones in oncogenesis and cell death. J Natl Cancer Inst 2000 Oct;92(19):1564-1572.

3. Calderwood SK, Khaleque MA, Sawyer DB, Ciocca DR. Heat shock proteins in cancer: chaperones of tumorigenesis. Trends Biochem Sci 2006 Mar;31(3):164-172.

4. Tekkesin M, Mutlu S, Aksakalli N, Olgac V. Expression of heat shock proteins 27, 60 and 70 in oral carcinogenesis: an immunohistochemical study. Turk Onkoloji Dergisi 2011;26(3):115-120.

5. Vidyasagar A, Wilson NA, Djamali A. Heat shock protein 27 (HSP27): biomarker of disease and therapeutic target. Fibrogenesis Tissue Repair 2012 May;5(1):7.

6. Lo Muzio L, Leonardi R, Mariggiò MA, Mignogna MD, Rubini C, Vinella A, Pannone G, Giannetti L, Serpico R, Testa $\mathrm{NF}$, et al. HSP 27 as possible prognostic factor in patients with oral squamous cell carcinoma. Histol Histopathol 2004 Jan;19(1):119-128.

7. Mohtasham N, Babakoohi S, Montaser-Kouhsari L, Memar B, Salehinejad J, Rahpeyma A, Khageh-Ahmady S, Marouzi P, Firooz A, Pazoki-Toroudi H, et al. The expression of heat shock proteins 27 and 105 in squamous cell carcinoma of the tongue and relationship with clinicopathological index. Med Oral Patol Oral Cir Bucal 2011 Sep;16(6):e730-e735.

8. Deyhimi P, Azmoudeh F. HSP27 and HSP70 expression in squamous cell carcinoma: an immunohistochemical study. Dent Res J (Isfahan) 2012 Mar;9(2):162-166.

9. Garcia-Garcia V, Bascones-Martínez A, García-Kass AI, Martinelli-Kläy CP, Küffer R, Álvarez-Fernández E, Lombardi T. Analysis of the expression of heat-shock protein 27 in patients with oral lichen planus. Oral Dis 2013 Jan;19(1):65-72.

10. Bhattacharya S, Chattopadhyay D, Raha S, Mukhopadhyay A. Multidimensional applications of heat shock proteins: a review of the perspectives for environment and health. IJIPLS 2012;2(3):345-355.

11. Suzuki H, Sugimura H, Hashimoto K. Overexpression of heat shock protein 27 is associated with good prognosis in the patient with oral squamous cell carcinoma. Br J Oral Maxillofac Surg 2007 Mar;45(2):123-129.

12. Mese H, Sasaki A, Nakayama S, Yoshioka N, Yoshihama Y, Kishimoto K, Matsumura T. Prognostic significance of heat shock protein 27 (HSP27) in patients with oral squamous cell carcinoma. Oncol Rep 2002 Mar-Apr;9(2):341-344.

13. Lo WY, Tsai MH, Tsai Y, Hua CH, Tsai FJ, Huang SY, Tsai $\mathrm{CH}$, Lai CC. Identification of over-expressed proteins in oral squamous cell carcinoma (OSCC) patients by clinical proteomic analysis. Clin Chem Acta 2007 Feb;376(1-2): 101-107.

14. Leonardi R, Pannone G, Magro G, Kudo Y, Takata T, Lo Muzio L. Differential expression of heat shock protein 27 in normal oral mucosa, oral epithelial dysplasia and squamous cell carcinoma. Oncol Rep 2002 Mar-Apr;9(2):261-266. 
15. Epivatianos A, Poulopoulos AK, Kayavis I, Papanayotou P. Expression of heat shock protein 27 (HSP-27) in oral dysplastic epithelium and squamous cell carcinoma. Balkan Journal of Stomatology 2001;5(2):111-114.

16. Seoane JM, Varela-Centelles PI, Ramirez JR, CameselleTeijeiro J, Romero MA, Aguirre JM. Heat shock proteins
(HSP70 and HSP27) as markers of epithelial dysplasia in oral leukoplakia. Am J Dermatopathol 2006 Oct;28(5):417-422.

17. Lee SS, Tsai CH, Ho YC, Yu CC, Chang YC. Heat shock protein 27 expression in areca quid chewing-associated oral squamous cell carcinomas. Oral Dis 2012 Oct;18(7): 713-719. 